\title{
Air Passengers' Continued Use Intention of the Airport E-Gate System: A Perspective with Perceived Benefits
}

\author{
Fang Yuan Chen $^{1} \&$ Chang Yu Liu ${ }^{1}$ \\ ${ }^{1}$ Department of Transportation and Logistics, College of Construction, Feng Chia University, Taiwan, ROC \\ Correspondence: Fang Yuan Chen, Department of Transportation and Logistics, College of Construction, Feng \\ Chia University, Taiwan, ROC. E-mail: fychen@fcu.edu.tw
}

Received: November 15, 2020

Accepted: December 16, 2020

Online Published: December 26, 2020

doi:10.5539/ijbm.v16n1p100

URL: https://doi.org/10.5539/ijbm.v16n1p100

\begin{abstract}
With the rapid development of air transportation in recent years, the number of national entry and exit passengers has hit record highs. Facing the increasingly busy airport, an automated border control system (E-gate) has been developed to provide faster and more convenient services. This study adopts the perspective of perceived benefits to explore the willingness of passengers to continuously use the E-Gate. In this study, a total of 539 valid questionnaires are collected at the Taoyuan International Airport in Taiwan. The SPSS 24 and AMOS 22 software are used for statistical analysis, and the hypotheses are verified by Structural Equation Modeling (SEM). The results show that perceived ease of use, perceived usefulness, and convenience have positive and significant effects on air passengers' continued use intention of E-gate, with convenience having the greatest impact, followed by perceived ease of use and perceived usefulness. The findings of this research can not only assist government agencies and airport operators in the development of better user-accepted immigration clearance systems, but can also provide insight into how to promote the new technology to potential users.
\end{abstract}

Keywords: E-gate, perceived ease of use, perceived usefulness, convenience, technology acceptance model

\section{Introduction}

Have you experienced long security lines at airports or grown tired of slow inspection at airports' border control? For security reasons, travel document inspection is an essential procedure to prevent illegal arrivals or departures. The traditional approach adopted by the airports around the world is to set up entry and exit checkpoints. Before allowing cross-border travels, immigration officers at the checkpoints will check the passenger's boarding pass and passport to verify their travel documents and the legality of their arrival or departure (Morosan, 2016). It is no doubt that the continued growth in global aviation demand is expected to increase the number of inbound and outbound air travelers. Long passenger queues for travel document inspection at the airports will be more common. This will not only increase passengers' waiting time but also lead to a decline in the quality of airport services and seriously harm the image of the airport (Farrell, 2016).

The recent advancement in information technology has facilitated speedier and more convenient options. Traditionally, the role of immigration officers in travel document inspection is to verify the authenticity of the passenger's passport, thereby checking whether the passenger is the legal holder of his or her passport (Morosan, 2016; Farrell, 2016). Increasingly, an automated border control system using the biometric technology has replaced the role of immigration officers in matching the travelers to the passport holders. Biometric technology verifies the identities of each passenger based on his or her physical and/or behavioral characteristics. Physical characteristics commonly used as biometrics include facial features, fingerprint, vein, iris, and DNA, while common behavioral characteristics include signature and voice. More and more airports in the United States, Europe and Asia have implemented similar technologies (Morosan, 2016). In 2012, Taiwan officially launched an automated immigration clearance system (thereafter called "E-gate"); passengers can use the system after completing the application and registration formalities of the automated system. The electronic system conducts automated verification of passengers' identities in a fully automated manner, allowing for a fast and convenient self-service process for border crossing. The technology reduces the average document inspection time from 30 to 12 seconds, which represents a substantial reduction in the border-crossing process. Yet, since the operation of the system, the utilization rate of the E-gate has not reached the expected target (National Immigration Agency, 2018). 
In addition to attracting passengers to use the E-gate, it is also important to understand why passengers continue to use and the factors that motivate them to do so. Continuance intention is consumers' intent to continually use a product, service, or system, which is different from initial adoption (Montazemi \& Qahri-Saremi, 2015; Zhou, 2013). Continuance intention is one type of behavioral intention expressed in different ways, such as repurchase intent, recommendation intent, and providing feedback (Hepola et al., 2020). Previous research has shown that the behavioral intention to use a technology must take into account the benefits or value perceived by consumers (Cheng et al., 2009; Fuchs et al. 2010). In this research, we propose that perceived benefits, which are positive drivers of value, are critical determinants for passengers to decide whether to continue using the E-gate.

Although it is apparent that the importance of the automated immigration clearance systems on a global scale is increasing, there are few studies investigating passengers' continuance intention in the Asia-Pacific region, where the growth of air transport demand is expected to rank first in the world in the next decade (Airports Council International, 2019). To fill the research gap, this study intends to investigate the factors affecting passengers' continuance intention of the E-gate from the perspective of perceived benefits. Specifically, we use perceived ease of use (PEOU) and perceived usefulness (PU), two core variables associated with consumer benefits in the Technology Acceptance Model (TAM), and convenience to explore the willingness of passengers to continue to use the E-gate. The results will help airport operators and system developers understand passengers' opinions on this new technology and the ways to improve and promote E-gate.

\section{Theoretical Background and the Development of Hypotheses}

Despite the spreading of the Coronavirus disease (COVID-19), global passenger traffic (RPKs) is expected to return to 2019 levels in 2024 (Pearce, 2020). It creates problems for airport operators, especially in security and immigration inspection. According to a SITA's recent report, passengers expressed that security inspections and border controls at the airport are the places most likely to trigger their negative experiences and emotions along all stages of air travel (Farrel, 2016). In addition to setting up checkpoints, a new biometric technology has appeared as an alternative at the airport, which can play a key role in solving this problem.

Biometrics are people's biological measurements or physical characteristics that can be used to identify an individual, which includes physiological features (e.g., fingerprints, shapes of face, eyes) and behavioral features (e.g., how you speak, walk, sit, or type) (Bolle et al., 2004). Due to the widespread use of electronic passports, facial and fingerprint recognitions are currently the two main technologies used in airport border control (Farrel, 2016). These unique biological characteristics can be used to accurately identify the true identity of passengers, thereby improving the safety of air travel. The accuracy, efficiency, and ease of operation of the biometric system make it the most suitable for identification and access control (Jain, 2007; Morosan, 2016). The biometric system is one of the latest technologies for airport exit and entry control. More and more airports have deployed this system to replace manual inspections, especially in Europe and Asia (Morosan, 2016).

Air passengers can choose to register in this system on a voluntary basis. Registered passengers are eligible for certain benefits, including the reduction of waiting time, faster and more secure processing, and enhancing the experience at the airport (Lazarick \& Cambier, 2008). However, there are still some problems associated with the use of biometric systems. For example, the way in which data is collected in each country, including when the data is collected and how the data is processed, may vary (Díaz, 2014). The laws and regulations governing the collection, storage, processing, exchange, and disposal of biometric information by organizations are still unclear. (Morosan, 2012). In addition, there will also have personal privacy and data protection issues in the process of collecting and processing personal information by the biometric systems (Díaz, 2014; Ioannou et al., 2020).

The Technology Acceptance Model (TAM) proposed by Davis (1989) is one of the technology-based theories, which is often used to explain individuals' information technology adoption behaviors (Yang et al., 2020). This model provides a theoretical basis for understanding the influence of external factors on users' internal beliefs, attitudes and intentions, thereby affecting the use of a technology. The TAM proposes that users' PEOU and PU of a technology will affect their attitudes of using the technology, and thus affect their intentions to use the information system. PEOU and PU are two key antecedents that explain users' acceptance of new systems or technologies. The TAM has a good theoretical basis, is simple and easy to understand, and has received much empirical support (Kim et al., 2010). Although the TAM is a widely adopted framework and has been tested and validated in research on technology acceptance and use, many studies have also expressed concern about using its initial form to explain user's intention to adopt the technology. It is recommended to add other external variables to the TAM to improve the accuracy of its prediction of technology adoption (Lu et al., 2009). In addition to POEU and PU, many studies have demonstrated that convenience is a crucial factor influencing users' 
decision to adopt or continue using new technologies (Kim \& Forsythe, 2008). In this study, we use POEU, PU, and convenience to predict air passenger s' continued use intention of the airport E-gate System.

PU refers to the degree to which users believe that using a certain system will increase their work performance or save effort (Davis et al., 1989). Previous research has found that individuals' perceptions of usability or usefulness provided by a technology affect their chances of continuing to use the technology (Sledgianowski \& Kulviwat, 2009; Pontiggia \& Virili, 2010). In their research, Lin and Wang (2012) advanced a model that probed into the relationships between perceived fit and system factors, which could inspire learners to continue to use the e-learning system. The findings revealed that PU contributes positively to continuance intention. Grounded on the Post-Acceptance Model of IS Continuance, Li and Liu (2014) developed a research framework to explore the key variables affecting consumers' different behaviors after they use the online travel services. The findings showed that PU positively affected continuance intention. Wang et al. (2012) extended The Five-Factor Model of Personality to the context of information system continuance. The findings supported that PU was a crucial factor to continued use intention of instant messaging. In air transport, the biometric systems deployed at the airports bring substantial benefits to both passengers and border control agencies with respect to "perceived usefulness", including processing speed, accuracy, and security (Morosan, 2016).

Within the initial framework of TAM, PEOU is another important determinant of technology acceptance. PEOU refers to the extent to which consumers believe that using a particular technology does not require much effort, i.e., easy to use (Davis, 1989). It is related to consumers' assessment of the effort required to use a technology

(Venkatesh, 2000). If a technology is too complex to use, it will reduce the willingness of users to adopt the technology (Rogers, 2003). Previous studies have found that ease of use is a key variable affecting continued use intention of a technology (Lin \& Filieri, 2015; Cho, 2016). Based on the TAM, Lin and Filieri (2015) examined the factors influencing air passengers' continued use intention of the online flight check-in service. The findings showed that the degree to which air passengers perceived the ease of use of the online flight check-in service had a positive impact on their continuance intentions. Based on the TAM, research by Huang and Ren (2020) attempted to understand the intention of existing customers to continue using the fitness mobile apps. The results revealed that PEOU had a positive impact on continued use intention of the fitness mobile apps. Drawing from the Post-Acceptance Model and the TAM, Cho (2016) developed a model to find out the antecedents that affected consumers' willingness to continue using the health apps. The results confirmed that PEOU was positively associated with consumers' willingness to continue using health apps on smartphones. In order to improve usage rate, the biometric systems deployed at the airports are designed to be user-friendly, so that passengers expect the systems to be mentally and physically free of effort when using the E-gate.

Perceived benefits usually refer to consumers' positive affirmation and feelings about the products or services (Sweeney and Soutar, 2001). In addition to actual functional outcomes, perceived benefits also include the psychological and social aspects consumers obtain from using the products or services (Yang et al., 2020). Sweeney and Soutar (2001) divided consumers' perceived benefits into functional benefits, emotional benefits, and social benefits. Tanadi et al. (2015) investigated how perceived benefits could improve the online intention of Generation Y in Malaysia. The four perceived benefits of shopping convenience, product selection, ease of shopping, and shopping enjoyment were used to test their influences on online intention. The findings confirmed that all aspects of perceived benefits had a positive impact on online intention. The study of Chaniotakis and Lymperopoulos (2006) investigated the role of perceived benefits in influencing the use of online banking by personal computer users in Greece. It turned out that the perceived benefits of Internet banking were the most important factors that affected consumers' intentions to use Internet banking services. According to Berry et al. (2002), service convenience depicts consumers' perceptions of the time and energy (i.e., sacrifice or psychological stress) associated with purchasing or using the service. They put forward a comprehensive multi-dimensional concept of service convenience: decision, access, transaction, benefit, and post-benefit. These five types of convenience mirror the activities of consumers when they purchase or use services. Consumers' time and energy expenditure on each type of service convenience have an impact on their overall convenience assessment. Researchers have confirmed that convenience is positively associated with continuous intention. Chang et al. (2013) used the one-group post-test design to explore the willingness of senior high school students to continue learning English through personal digital assistants. The results revealed that convenience was positively related to the intention to continue using the personal digital assistants. Based on the benefit-risk framework and network externality theory, Lee and Kim (2020) proposed a research framework to investigate the key antecedents influencing consumers' intention to use or continue to use Internet-only banks. The results revealed that convenience experienced in the post-adoption stage exerted a positive effect on consumer's willingness to continue to use. 
Based on a review of the above literature, we propose three hypotheses as follows:

$\mathrm{H}_{1}$ : There is a positive relationship between air passengers' perceived ease of use and their continued use intention of the E-gate.

$\mathrm{H}_{2}$ : There is a positive relationship between air passengers' perceived usefulness and their continued use intention of the E-gate.

$\mathrm{H}_{3}$ : There is a positive relationship between air passengers' perceived convenience and their continued use intention of the E-gate.

\section{Methodology}

\subsection{Sample and Data Collection}

As shown in Figure 1, the conceptual framework includes three independent variables: PEOU, PU, and convenience, which represent the perceived benefits of passengers using the E-gate, and continuous intention is the dependent variable. We conducted a self-administered questionnaire survey to collect data using convenience sampling techniques to select passengers to fill out the questionnaires. In March 2019, a face-to-face interview was administered at Taoyuan International Airport (Taiwan's largest airport) for a period of two weeks. The respondents were approached while they were waiting for check-in and asked whether they had ever used the E-gate. Only those who responded positively were briefed on the reason and objective of the investigation and were invited to assist in the survey. Six hundred questionnaires were distributed and returned. A total of five hundred and thirty-nine completed questionnaires were obtained for further analysis, producing a satisfactory response rate of $90 \%$. During the implementation of the survey, we constantly changed the survey administration locations and conducted the survey during both peak and non-peak hours of the day with the aim of obtaining a more relevant sample.

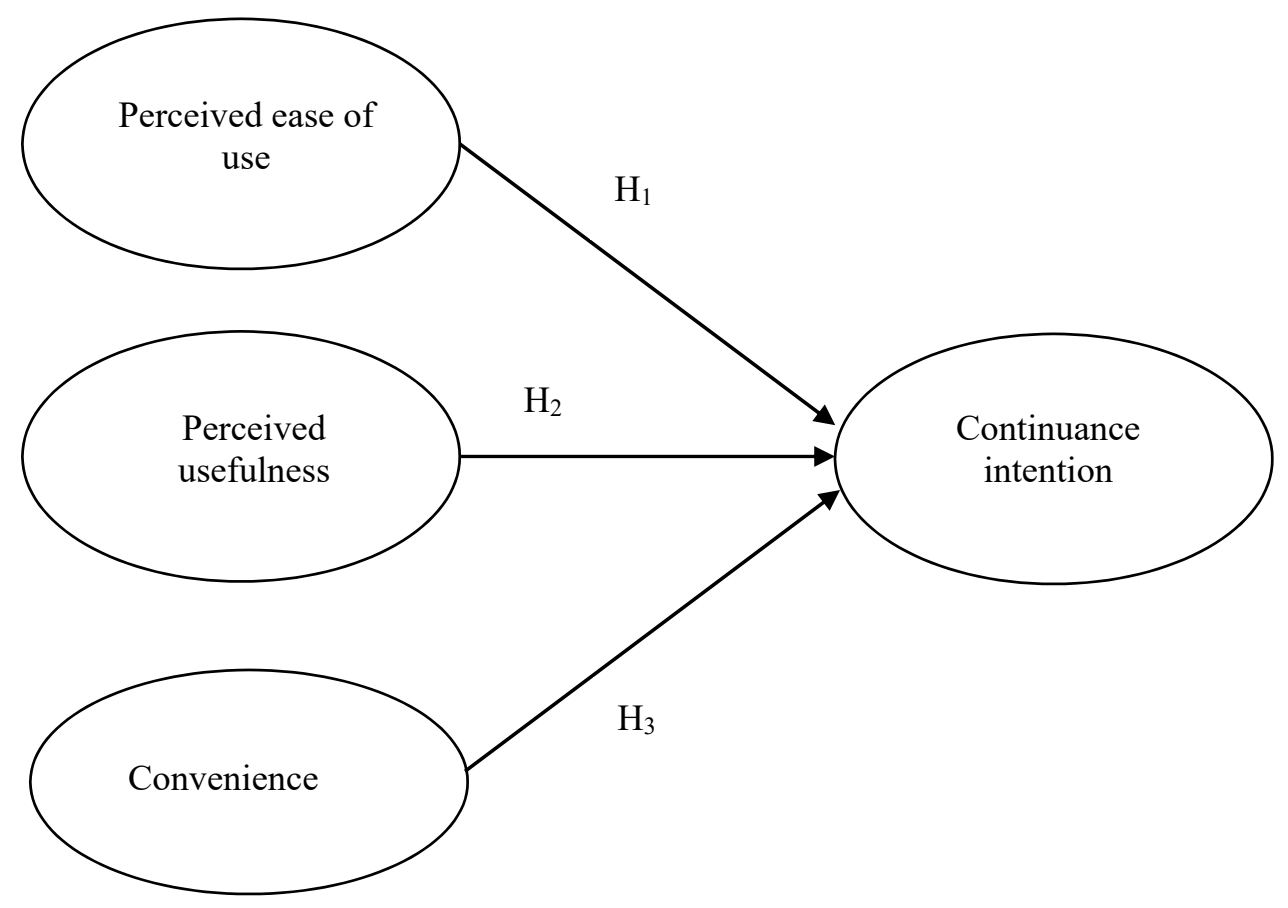

Figure 1. Research model

\subsection{Measures}

Because the survey was conducted in Taiwan, the measures originally written in English were translated and back-translated by two independent researchers to ensure item equivalency. The measures were drawn form past research related to the TAM and its extensions. The questionnaire items were further revised to reflect the specific service context under study. To assure content validity, we asked three university colleagues who were familiar with technology adoption to comment on the suitability of the wordings of each item. Minor changes were subsequently made to the items due to the subtleties of the Chinese characters. The content validity of the questionnaire was considered adequate. Prior to the formal survey, we conducted a pilot study and asked twenty 
respondents who had used the E-gate to evaluate the items of the initial questionnaire. The questionnaire items were revised according to the opinions obtained from the pilot test. We then translated the final Chinese version of the questionnaire back to English to ensure that the items were equivalent.

The study instrument was composed of two parts, including the items related to the independent and dependent variables and the socio-demographic characteristics of the respondents (e.g., age, gender, monthly income). Five items measuring PEOU were adapted from Venkatesh (2000) and Cho \& Sagynov (2015), while PU was based on Davis (1989) \& Morosan (2014). Convenience was measured with four items based on Lee and Kim (2020). Finally, the four-item continuance intention scale was based on the work of Bhattacherjee (2001) \& Morosan (2014). After reading the questionnaire items, the respondents rated each item based on their own perceptions using a 5 -point Likert-type scale $(1=$ strongly disagree to $5=$ strongly agree $)$.

\subsection{Data Analyses}

We used the structural equation modeling technique to analyze the data (Anderson \& Gerbing, 1988). A confirmatory factor analysis was first performed to evaluate the measurement model, followed by a structural model that analyzed the hypothesized relationships among the study variables. Different indicators were used to verify whether the data meets the threshold requirements of the measurement model and structural model (Anderson \& Gerbing, 1988). The statistical software packages SPSS 20.0 and AMOS 20.0 were used to perform data analysis.

\section{Results}

There were slightly more women (51.4\%) than men (48.6\%) in the final sample. Respondents came from a variety of occupations including students, technology industry, service industry, financial industry, manufacturing, public servants, and housekeeping. The age of the respondents were mostly from the range of 20-30 years old (31.9\%), followed by 31-40 years old (29.9\%) and 41-50 years old (21.2\%). They were fairly evenly spread over average monthly income brackets (i.e., $<=23,100$ NTD, 23,101-40,000 NTD, 40,001-60,000 NTD, $60,001-80,000,80,001-100,000$ NTD). In terms of traveling purpose, the proportions were also equally distributed across business, leisure, and visiting friends and relatives. The sample was primarily composed of well-educated customers; nearly eighty-seven percent of the respondents graduated from college/university and above. The main reasons for the respondents to use the E-gate were to save clearance time (79.6\%), easy to operate $(7.8 \%)$, and a sense of novelty $(5.6 \%)$, with only $0.6 \%$ hoping to keep up with the world trend.

Cronbach's alpha was used as an indicator of the internal consistency or reliability of a research construct. We used principal component analysis with orthogonal factor rotation to evaluate the reliability of the research constructs. All of the factor loadings were greater than 0.5 (Hair et al., 2006) and no cross-loadings were found. All values of Cronbach's alpha for the research constructs were above the recommended threshold 0.7 , which were acceptable (Hair et al., 2006).

A confirmatory factor analysis (CFA) was performed to evaluate the measurement model. The size of the factor loading is one of the criteria used to evaluate the reliability of the indicator with the construct it intends to measure (Hair et al., 2006). One item of PEOU and one item of PU showed factor loadings that failed to exceed the conservative threshold of 0.60 (Fornell \& Larcker, 1981) and consequently were eliminated. All other item loadings were higher than the threshold of 0.7 and were significant (Hair et al., 2006). After eliminating the two items, all indices were within the recommended range to support an acceptable measurement model: $\chi^{2}(59)=$ $130.7(\mathrm{p}<0.001) ; \chi^{2} / \mathrm{df}=2.217 ; \mathrm{GFI}=0.965 ;$ AGFI $=0.946 ; \mathrm{CFI}=0.984 ; \mathrm{NFI}=0.971 ; \mathrm{TLI}=0.979 ; \mathrm{RMR}=$ 0.011 ; RMSEA $=0.048$. Convergent validity was satisfied because all standardized factor loadings for the corresponding construct were significant and most of the items' squared multiple correlations were above the cut-off value of 0.50 (Anderson \& Gerbing, 1988). The means, standard deviations, and inter-correlations between the research constructs are presented in Table 1. Further, the average variance extracted (AVE) of all constructs were above the minimum criterion of 0.50 , indicating evidence of convergent validity. Composite reliability was evaluated to assess the internal consistency of the research constructs. As shown in Table 2, composite reliability of all of the constructs were higher than the recommended value of 0.70 (Hair et al., 2006), indicating adequate internal consistency for each construct. Discriminant validity was also achieved because the squared root of the average variance extracted of each construct was larger than the correlation between any pair of constructs (Fornell \& Larcker, 1981). Following the measurement model, the structural model was estimated and examined with the same fit indices. The results as indicated by these indices were considered satisfactory and showed a good fit to the data: $\chi^{2}(58)=273 ; \chi^{2} / \mathrm{df}=4.7$; GFI $=0.945 ;$ AGFI $=0.913 ; \mathrm{CFI}=0.951$; $\mathrm{NFI}=$ 0.939 ; TLI $=0.935 ;$ RMR $=0.13$; RMSEA $=0.083$. Except for the slightly higher RMR value, most indices met the standards proposed by scholars. Hair et al. (2006) suggest that the model is acceptable as long as most of the 
fit indices meet the threshold. Table 3 presents the results of the hypothesis testing in the structural model. Significant effects influencing continuance intention from PEOU, PU, and convenience were observed. As predicted in $\mathrm{H}_{1}$, there was a positive and significant relationship between PEOU and continuance intention $(\beta=$ $0.139, \mathrm{p}<0.01) . \mathrm{H}_{1}$ was supported. As expected in $\mathrm{H}_{2}$, the path from PU to continuance intention was positive and significant $(\beta=0.128, \mathrm{p}<0.05)$, thus supporting $\mathrm{H}_{2}$. Finally, the link between convenience and continuance intention was also positively significant $(\beta=0.321, \mathrm{p}<0.001)$. This hypothesis $\left(\mathrm{H}_{3}\right)$ was also confirmed. The results from the structural model revealed that convenience exhibited the strongest influence on continuance intention $(\beta=0.321)$, followed by PEOU $(\beta=0.139)$ and PU $(\beta=0.128)$. Finally, $29.7 \%$ of the variance in continuance intention was explained by PEOU, PU, and convenience, which is a moderate value (Fig. 2).

Table 1. Means, standard deviations, and inter-correlations ${ }^{\mathrm{a}}$

\begin{tabular}{|c|c|c|c|c|c|c|}
\hline & Mean & $\begin{array}{l}\text { Standard } \\
\text { deviation }\end{array}$ & 1 & 2 & 3 & 4 \\
\hline $1 \mathrm{PEOU}$ & 4.398 & 0.646 & $0.758^{b}$ & & & \\
\hline $2 \mathrm{PU}$ & 4.630 & 0.568 & $0.561 * *$ & $0.848^{b}$ & & \\
\hline 3 Convenience & 4.570 & 0.583 & $0.531 * *$ & $0.769 * *$ & $0.783^{b}$ & \\
\hline 4 Continuance intention & 4.513 & 0.606 & $0.529 * *$ & $0.594 * *$ & $0.561 * *$ & $0.885^{b}$ \\
\hline
\end{tabular}

**Parameter estimate is significant at the 0.01 level.

${ }^{\text {a }}$ Inter-correlations are estimates from AMOS output.

${ }^{\mathrm{b}}$ The value represents the squared root of the average variance of each construct.

Table 2. Measurement model results

\begin{tabular}{|c|c|c|c|c|c|}
\hline Construct & Item & $\begin{array}{l}\text { Standardized } \\
\text { loading }\end{array}$ & $\begin{array}{l}\text { Variance } \\
\text { explained }\end{array}$ & $\begin{array}{l}\text { Composite } \\
\text { reliability }\end{array}$ & $\begin{array}{l}\text { Average } \\
\text { variance } \\
\text { extracted }\end{array}$ \\
\hline \multirow[t]{4}{*}{ PEOU } & It is easy to apply for the E-gate. & $0.682 * * *$ & 0.566 & 0.842 & 0.574 \\
\hline & $\begin{array}{l}\text { I don't need the assistance of others to use } \\
\text { the E-gate. }\end{array}$ & $0.708 * * *$ & 0.552 & & \\
\hline & It is easy to be proficient in using the E-gate. & $0.791 * * *$ & 0.626 & & \\
\hline & Overall, I think the E-gate is easy to use. & $0.838 * * *$ & 0.703 & & \\
\hline \multirow[t]{3}{*}{ PU } & $\begin{array}{l}\text { Using the E-gate can speed up the } \\
\text { immigration clearance. }\end{array}$ & $0.846^{* * *}$ & 0.716 & 0.885 & 0.719 \\
\hline & Using the E-gate can save me time. & $0.887 * * *$ & 0.787 & & \\
\hline & $\begin{array}{l}\text { The E-gate meets my needs for fast entry } \\
\text { and exit when passing through immigration. }\end{array}$ & $0.809 * * *$ & 0.655 & & \\
\hline \multirow[t]{3}{*}{ Convenience } & $\begin{array}{l}\text { The use of E-gate can complete the } \\
\text { immigration clearance easily and quickly. }\end{array}$ & $0.807 * * *$ & 0.652 & 0.825 & 0.613 \\
\hline & $\begin{array}{l}\text { The use of E-gate can shorten the waiting } \\
\text { time in line }\end{array}$ & $0.694 * * *$ & 0.582 & & \\
\hline & $\begin{array}{l}\text { Overall, I think it is convenient and } \\
\text { beneficial to use the E-gate. }\end{array}$ & $0.840 * * *$ & 0.706 & & \\
\hline \multirow[t]{3}{*}{$\begin{array}{l}\text { Continuance } \\
\text { intention }\end{array}$} & $\begin{array}{l}\text { I am willing to continue to use the E-gate in } \\
\text { the future. }\end{array}$ & $0.888 * * *$ & 0.789 & 0.915 & 0.783 \\
\hline & $\begin{array}{l}\text { I would recommend my relatives and friends } \\
\text { to use the E-gate. }\end{array}$ & $0.868 * * *$ & 0.754 & & \\
\hline & $\begin{array}{l}\text { Overall, I am willing to continue to use the } \\
\text { E-gate. }\end{array}$ & $0.898 * * *$ & 0.807 & & \\
\hline
\end{tabular}


Table 3. Results of hypotheses testing

\begin{tabular}{lllll}
\hline Hypotheses & Paths & Standardized path coefficient & p-value & Results \\
\hline $\mathrm{H}_{1}$ & $\begin{array}{l}\text { Perceived ease of use } \rightarrow 0.139 \\
\text { Continuance intention }\end{array}$ & $* *$ & Supported \\
$\mathrm{H}_{2}$ & $\begin{array}{l}\text { Perceived usefulness } \rightarrow 0.128 \\
\text { Continuance intention } \\
\text { Convenience } \rightarrow \text { Continuance } \\
\text { intention }\end{array}$ & $* .321$ & $*{ }^{* * *}$ & Supported \\
&
\end{tabular}

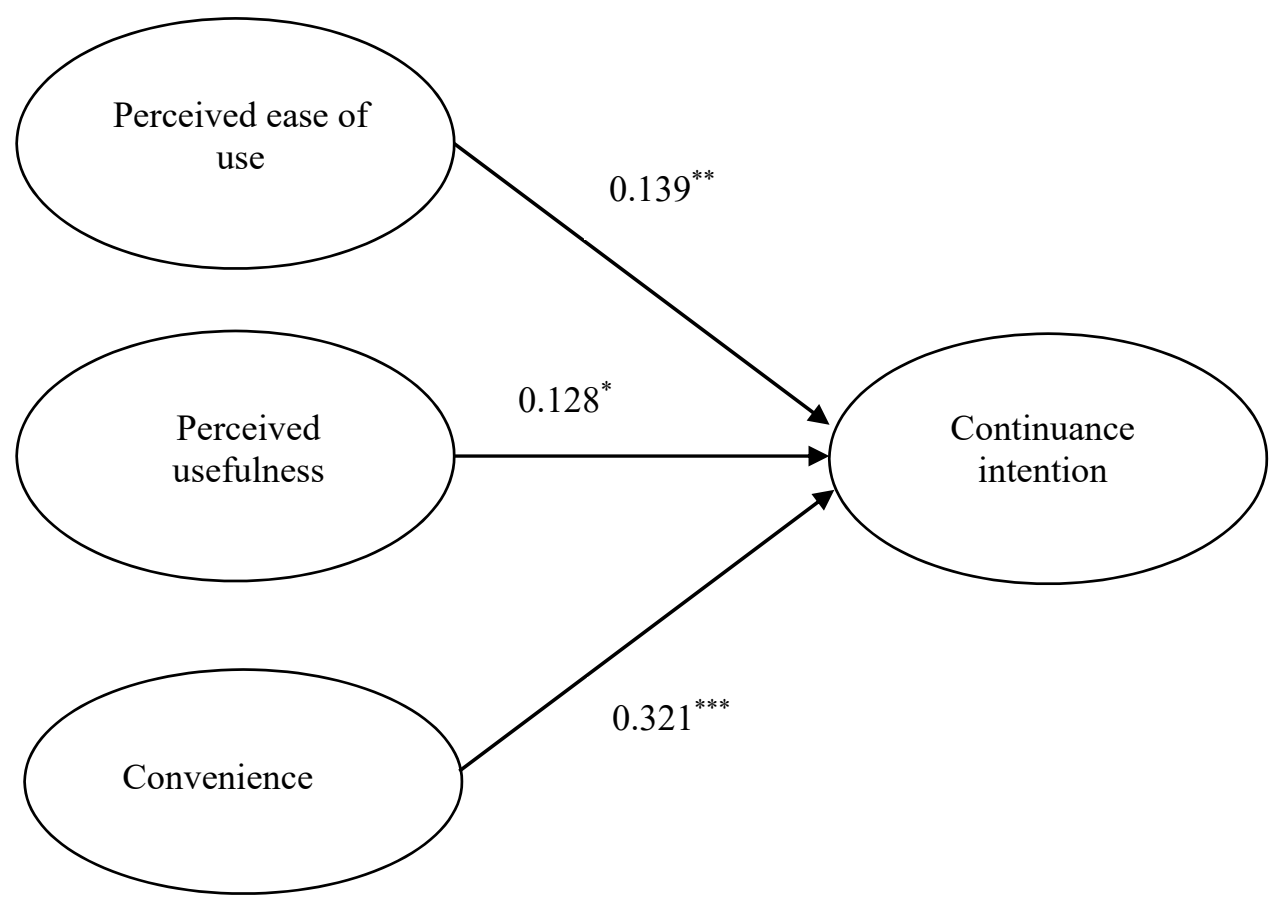

Figure 2. Results of the structural model

*Parameter estimate is significant at the 0.05level.

**Parameter estimate is significant at the 0.01 level.

***Parameter estimate is significant at the 0.001 level.

\section{Conclusions}

In this research, we set out to investigate the factors that motivate passengers to continue using the E-gate at the airport in Taiwan from the perspective of perceived benefits. To the best of our knowledge, our work is one of the first studies to investigate the impact of perceived benefits on repeated use intention after the first adoption of the E-gate. The benefits experienced by passengers include PEOU, PU, and convenience. The research findings reveal that there these benefits exert a positive and significant impact on passengers' continuance intention of using the E-gate, respectively, with convenience having the greatest impact, followed by PEOU and PU. These findings fully demonstrate that perceived benefits passengers get from using the E-gate can increase the value of the system, thereby enhancing their willingness to continue using the E-gate. The results echo previous studies and reaffirm the significant impact of PEOU and PU on the continued use of new technologies (Wu \& Wang, 2005; Luarn \& Lin, 2005; Morosan, 2012). When the E-gate is easy to operate, it will make it easier for passengers to learn and have a higher willingness to continue using it. To be useful, the E-gate must be able to quickly and accurately ascertain the identity of the passenger and speed up the clearance processing. When innovative technologies such as the E-gate can meet the needs of passengers, the chances for adopting such technologies will increase. In sum, the results signify that the more passengers feel the E-gate are useful and easy to operate, they are more likely to continue using it.

This study also supports the hypothesis that convenience has a significant impact on the continued willingness of air passengers to use the E-gate. The more convenient and time-saving the E-gate is for passengers, the higher their willingness to continue to use it. Furthermore, convenience shows the greatest influence on passengers' 
continuance intention of the E-gate, which illustrates the importance of the E-gate in reducing passengers' waiting time and providing convenient and efficient immigration inspection processing when entering and leaving the country. It is recommended that the immigration and airport authorities adopt such measures as simplifying the application procedures, increasing the number of the E-gate, and re-designing the moving lines to shorten waiting time for passengers, so that passengers can feel the benefits of convenience. They can also emphasize the convenience advantage of using the E-gate in their external promotional materials to attract passengers who have never used it. For system developers, how to enhance the convenience of the E-gate is the primary task, such as increasing the processing speed of the system to improve the efficiency of passenger clearance.

Conclusively, to increase the reuse rate of the E-gate, the benefits that passengers can obtain should be emphasized, such as PEOU, PU and convenience. Airport operators and system developers should convey the message to air passengers that the use of E-Gate is beneficial because it can provide faster, more convenient, and more efficient immigration clearance services, which will lead to a better overall airport experience. Additionally, the design of the electronic gate should be as humane as possible, not to confuse users, and must ensure that they can use it without much effort.

As in any other research, this study has certain limitations. First, the respondents are recruited only in Taiwan. If respondents from other countries are selected for this study, the results of the survey may be different due to cultural differences. Therefore, it is advised that future research exercise caution when interpreting and generalizing the findings of our work. Second, the original TAM was proposed to investigate work-related or task environment, which is different from the research setting of this study. Therefore, the predicted results may be different. Lastly, in light of the moderate variance explained by our model, we suggest that more relevant constructs be considered in future research to obtain further insights into air passengers' intention to continue using the E-gate.

\section{Acknowledgement}

The study is part of the research results which has been presented at the 2019 Annual Conference of the Chinese Institute of Transportation (Taiwan). The authors would like to thank the reviewers of the Annual Conference and International Journal of Business and Management for their valuable comments and suggestions.

\section{References}

Airports Council International. (2019). Annual World Airport Traffic Report.

Anderson, J. C., \& Gerbing, D. W. (1988). Structural equation modeling in practice: a review and recommended two-step approach. Psychological Bulletin, 103(3), 411-423. https://doi.org/10.1037/0033-2909.103.3.411

Berry, L. L., Seiders, K., \& Grewal, D. (2002). Understanding service convenience. Journal of Marketing, 66(3), 1-17. https://doi.org/10.1509/jmkg.66.3.1.18505

Bhattacherjee, A. (2001). Understanding information systems continuance: An expectation-confirmation model. MIS Quarterly, 25(3), 351-370. https://doi.org/10.2307/3250921

Bolle, R. M., Connell, J. H., Pakanti, S., Ratha, N. K., \& Senior, A. W. (2004). Guide to Biometrics. New York: Springer.

Chang, C. C., Tseng, K. H., Liang, C., \& Yan, C. F. (2013). The influence of perceived convenience and curiosity on continuance intention in mobile English learning for high school students using PDAs. Technology, Pedagogy and Education 22(3), 373-386. https://doi.org/10.1080/1475939X.2013.802991

Chaniotakis, I. E. (2006). The importance of perceived benefits in intentions to use Internet banking among Greek PC users. Journal of Customer Behaviour, 5(3), 267-283. https://doi.org/10.1362/147539206779656832

Cheng, J. M. S., Wang, E. S. T., Lin, J. Y. C., \& Vivek, S. D. (2009). Why do customers utilize the Internet as a retailing platform? A view from customer perceived value. Asia Pacific Journal of Marketing and Logistics 21(1), 144-160. https://doi.org/10.1108/13555850910926290

Cho, J. (2016). The impact of post-adoption beliefs on the continued use of health apps. International Journal of Medical Informatics, 87, 75-83. https://doi.org/10.1016/j.ijmedinf.2015.12.016

Cho, Y. C., \& Sagynov, E. (2015). Exploring factors that affect usefulness, ease of use, trust, and purchase intention in the online environment. International Journal of Management \& Information Systems, 19(1), 21-36. https://doi.org/10.19030/ijmis.v19i1.9086 
Davis, F. D. (1989). Perceived usefulness, perceived ease of use, and user acceptance of information technology. MIS Quarterly, 13(3), 319-340. https://doi.org/10.2307/249008

Díaz, V. (2014). Legal challenges of biometric immigration control systems. Mexican Law Review, 12(1), 3-30. http://dx.doi.org/10.1016/S1870-0578(16)30006-3

Farrel, S. (2016). How airports can fly to self-service biometrics. Biometric Technology Today, (1), 5-7. https://doi.org/10.1016/S0969-4765(16)30016-9

Fornell, C., \& Larcker, D. F. (1981). Evaluating structural equation models with unobservable and measurement error. Journal of Marketing Research, 18(1), 39-50. https://doi.org/10.2307/3151312

Fuchs, M., Hopken, W., Foger, A., \& Kunz, M. (2010). E-business readiness, intensity, and impact: An Austrian destination management organization study. Journal of Travel Research, 49(2), 165-78. https://doi.org/10.1177/0047287509336469

Hair, J., Black, W., Babin, B., Anderson, R., \& Tatham, R. (2006). Multivariate Data Analysis (6th ed.). Pearson Prentice Hall, Upper Saddle River.

Hepola, J., Leppäniemi, M., \& Karjaluoto, H. (2020). Is it all about consumer engagement? Explaining continuance intention for utilitarian and hedonic service consumption. Journal of Retailing and Consumer Services, 57, 102232. https://doi.org/10.1016/j.jretconser.2020.102232

Huang, G., \& Ren, Y. (2020). Linking technological functions of fitness mobile apps with continuance usage among Chinese users: moderating role of exercise self-efficacy. Computers in Human Behavior, 103, 151-160. https://doi.org/10.1016/j.chb.2019.09.013

Ioannou, A., Tussyadiah, I., \& Lu, Y. (2020). Privacy concerns and disclosure of biometric and behavioral data for travel. International Journal of Information Management 54, 102-122. https://doi.org/10.1016/j.ijinfomgt.2020.102122

Jain, A. K. (2007). Biometric recognition. Nature, 449, 38-40.

Kaabachi, S., \& Obeid, H. (2016). Determinants of Islamic banking adoption in Tunisia: empirical analysis. International Journal of Bank Marketing, 34(7), 1069-1091. https://doi.org/10.1108/IJBM-02-2015-0020

Kim, J., \& Forsythe, S. (2008). Sensory enabling technology acceptance model (SE-TAM): A multiple-group structural model comparison. Psychology \& Marketing, 25(9), 901-922. https://doi.org/10.1002/mar.20245

Kim, C., Mirusmonov, M., \& Lee, I. (2010). An empirical examination of factors influencing the intention to use mobile payment. Computers in Human Behavior, 26(3), 310-322. https://doi.org/10.1016/j.chb.2009.10.013

Lazarick, R, Jim L., \& Cambier, J. L. (2008). Biometrics in the Government Sector. In A. K. Jain, P. Flynn, \& A. A. Ross (Eds.), Handbook of Biometrics (pp. 461-478). New York: Springer.

Lee, J. M., \& Kim, H. J. (2020). Determinants of adoption and continuance intentions toward Internet-only banks. International Journal of Bank Marketing, 38(4), 843-865. https://doi.org/10.1108/IJBM-07-2019-0269

Li, H., \& Liu, Y. (2014). Understanding post-adoption behaviors of e-service users in the context of online travel services. Information \& Management, 51(8), 1043-1052. https://doi.org/10.1016/j.im.2014.07.004

Lin, Z., \& Filieri, R. (2015). Airline passengers' continuance intention towards online check-in services: The role of personal innovativeness and subjective knowledge. Transportation Research Part E: Logistics and Transportation Review, 81, 158-168. https://doi.org/10.1016/j.tre.2015.07.001

Lin, W. S., \& Wang, C. H. (2012). Antecedences to continued intentions of adopting e-learning system in blended learning instruction: A contingency framework based on models of information system success and task-technology fit. Computers \& Education, 58(1), 88-99. https://doi.org/10.1016/j.compedu.2011.07.008

Lu, J. L., Chou, H. Y., \& Ling, P. C. (2009). Investigating passengers' intentions to use technology-based self check-in services. Transportation Research Part E: Logistics and Transportation Review, 45(2), 345-356. https://doi.org/10.1016/j.tre.2008.09.006

Luarn, P., \& Lin, H. H. (2005). Toward an understanding of the behavioral intention to use mobile banking. Computers in Human Behavior, 21(6), 873-891. https://doi.org/10.1016/j.chb.2004.03.003

Moon, J. W., \& Kim, G. (2001). Extending the TAM for a World-Wide-Web context. Information \& Management, 38(4), 217-230. https://doi.org/10.1016/S0378-7206(00)00061-6 
Montazemi, A. R., \& Qahri-Saremi, H. (2015). Factors affecting adoption of online banking: a meta-analytic structural equation modeling study. Information \& Management, 52(2), 210-226. https://doi.org/10.1016/j.im.2014.11.002

Morosan, C. (2012). Voluntary steps toward air travel security: An examination of travelers' attitudes and intentions to use biometric systems. Journal of Travel Research, 51(4), 436-450. https://doi.org/10.1177/0047287511418368

Morosan, C. (2014). Toward an integrated model of adoption of mobile phones for purchasing ancillary services in air travel. International Journal of Contemporary Hospitality Management, 26(2), 246-271. https://doi.org/10.1108/IJCHM-11-2012-0221

Morosan, C. (2016). An empirical examination of U.S. travelers' intentions to use biometric e-gates in airports. Journal of Air Transport Management, 55, 120-128. https://doi.org/10.1016/j.jairtraman.2016.05.005

National Immigration Agency, Ministry of Interior. (2018). Travelling has never been so convenient! Retrieved from https://www.immigration.gov.tw/5475/5478/141457/141990/142037/

Pearce, B. (2020). COVID-19: Outlook for air travel in the next 5 years. International Air Transport Association.

Pontiggia, A., \& Virili, F. (2010). Network effects in technology acceptance: laboratory experimental evidence. $\begin{array}{lllll}\text { International Journal of Information } & \text { Management, } & 30(1), & \text { 68-77. }\end{array}$ https://doi.org/10.1016/j.ijinfomgt.2009.07.001

Rogers, E. M. (2003). Diffusion of Innovations (5th ed.), New York, NY: Free Press.

Raman, P., 2019. Understanding female consumers' intention to shop online: The role of trust, convenience and customer service. Asia Pacific Journal of Marketing and Logistics, 31(4), 1138-1160. https://doi.org/10.1108/APJML-10-2018-0396

Sledgianowski, D., \& Kulviwat, S. (2009). Using social network sites: the effects of playfulness, critical mass and trust in a hedonic context. Journal of Computer Information Systems, 49(4), 74-83. https://doi.org/10.1080/08874417.2009.11645342

Sweeney, J. C., \& Soutar, G. (2001). Consumer perceived value: the development of a multiple item scale. Journal of Retailing, 77(2), 203-220. https://doi.org/10.1016/S0022-4359(01)00041-0

Tanadi, T., Samadi, B, \& Gharleghi, B. (2015). The Impact of Perceived Risks and Perceived Benefits to Improve an Online Intention among Generation-Y in Malaysia. Asian Social Science, 11(26), 226-238. https://doi.org/10.5539/ass.v11n26p226

Venkatesh, V. (2000). Determinants of perceived ease of use: integrating control, intrinsic motivation, and emotion into the technology acceptance model. Information Systems Research, 11(4), 342-365. https://doi.org/10.1287/isre.11.4.342.11872

Wang, W., Ngai, E. W. T., \& Wei, H. (2012). Explaining instant messaging continuance intention: the role of personality. International Journal of Human-Computer Interaction, 28(8), 500-512. https://doi.org/10.1080/10447318.2011.622971

Wu, J. H., \& Wang, S. C. (2005). What drives mobile commerce? An empirical evaluation of the revised technology acceptance model. Information \& Management, 42(5), 719-729. https://doi.org/10.1016/j.im.2004.07.001

Yang, Y., Gong, Y., Land, L. P. W., \& Chesney, T. (2020). Understanding the effects of physical experience and information integration on consumer use of online to offline commerce. International Journal of Information Management, 51, 102046. https://doi.org/10.1016/j.ijinfomgt.2019.102046

Zhou, T., 2013. An empirical examination of continuance intention of mobile payment services. Decision Support Systems, 54(2), 1085-1091. https://doi.org/10.1016/j.dss.2012.10.034

\section{Copyrights}

Copyright for this article is retained by the author(s), with first publication rights granted to the journal.

This is an open-access article distributed under the terms and conditions of the Creative Commons Attribution license (http://creativecommons.org/licenses/by/4.0/). 